\title{
Method to quantitate intestinal metaplasia of stomach by image analysis
}

\author{
C A RUBIO, A PORWIT, M RODENSJÖ The Department of Pathology, Karolinska Sjukhuset, \\ Stockholm, Sweden
}

SUMMARY With the aid of an image quantifier, the distribution of histochemically labelled (alcian blue, $\mathrm{pH} 2.5$ ) mucin-producing goblet cells was recorded from a gastrectomy specimen with a peptic ulcer to determine the degree of metaplasia. Of 254 measurements made, 130 were in the antrum and 124 in the fundic area. The areas occupied by cells positive for alcian blue were $7 \cdot 5$ (SD 9.89)\% in the antral region, and $1.8(1.84) \%$ and $0.92(1.15) \%$ in the two zones representing the fundic area. The difference between the positive mucosal areas in the antrum was significantly higher $(p<0.001)$ than in the fundic area. The positively stained area found along the lesser curvature was $7 \cdot 76(12 \cdot 0) \%$ while along the greater curvature, it was $2 \cdot 17(3.02) \%(p<0.001)$.

This method will be useful for future studies of the extent and topographical distribution of intestinal metaplasia among populations with disparate incidences of gastric carcinoma because it permits comparison of different areas of intestinal metaplasia in mucous gastric zones.

The clinical importance of intestinal metaplasia of the stomach and its association with subsequent gastric carcinogenesis has been the subject of debate, ${ }^{1-15}$ but little effort has been made to quantify the distribution of goblet cells (which indicate metaplasia) in the gastric mucosa, with or without carcinoma. All studies to date concern non-quantitative estimates based on subjective visual impressions or approximative "calculations" in gastric biopsy specimens ${ }^{211}$ in surgically resected stomachs, ${ }^{4916}$ or at necropsy. ${ }^{6}$

To assess the role of intestinal metaplasia in the histogenesis of gastric carcinoma it is important to measure its extent and topographic distribution in those ethnic groups with a high or low incidence of gastric carcinoma.

We previously investigated the prevalence of goblet cells in gastric biopsy specimens from 986 Swedish and Japanese patients who had inflammatory changes." We found that goblet cells in the gastric mucosa occurred twice as often in the Japanese (an ethnic group with a high incidence of gastric carcinomas) as the Swedes (a population with a relatively low and rapidly decreasing incidence of gastric carcinoma). In another study we quantified intestinal metaplasia in $\mathbf{5 0}$ resected stomachs from Japanese patients who had peptic ulcers and carcinoma. ${ }^{10}$ Using a graphic electronic calculator we registered the mucosal areas with goblet cells and the length of the mucosa, constructing

Accepted for publication 26 January 1988 an intestinal metaplasia index (IMI) - that is, the ratio between intestinal metaplasia and the actual length of gastric mucosa analysed in each specimen.

More recently we reported a morphometric linear correlation between the actual length of intestinal metaplasia and the total length of mucosa analysed in each section, using a mucin-specific stain. ${ }^{2}$ A disadvantage of that procedure is that the gastric mucosa is measured linearly and is one dimensional. Mucinproducing gastric cells in intestinal metaplasia are not linearly arranged, but also occupy deeper areas of the gastric mucosa, so a procedure able to encompass the deeper mucosal areas is. needed.

With this in mind we developed a two dimensional method of quantifying mucosal areas with intestinal metaplasia in the gastric mucosa using an image analyser.

\section{Material and methods}

From a total of 52 gastrectomy specimens, one randomly chosen specimen with a gastric peptic ulcer was investigated. After fixation the specimen was put. on to a specially devised translucent grid pattern (figure) and placed on a photocopier with adaptable speeds (3M 830), with the pylorus placed on one of the distal transversal lines. The units in the translucent grid pattern (measuring $2.5 \times 0.5 \mathrm{~cm}$ ) were given consecutive numbers starting in the near pyloric region (figure) and ending in the proximal fundic region (figure). The specimen was then put on to the 


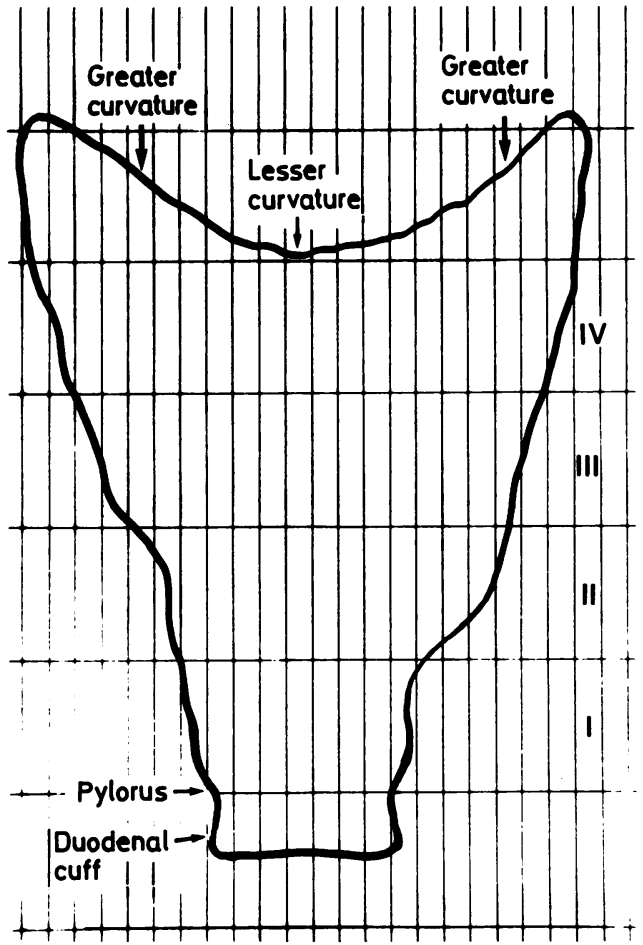

Figure Specially devised translucent grid pattern used for sectioning gastrectomy specimens into blocks. Units measured $2.5 \times 0.5 \mathrm{~cm}$. Transversal lines divide specimen into four zones: (i) all sections from the pyloric area with distal surgical resection; (ii) area adjacent to the pyloric area; (iii) gastric area proximal to zone II; and

(iv) proximal zone, including proximal surgical resection margin.

numbered photocopy and sectioned with a knife, following the lines of the pattern. Each block was processed separately. Two sections were taken from each block, one stained with haematoxylin and eosin and the other with alcian blue, $\mathrm{pH} 2 \cdot 5$ (to detect acid mucins) without counterstain.

The quantitation was based on the areas with alcian blue positive, mucin-producing goblet cells.

\section{IMAGE QUANTIFIER ANALYSIS}

Each section was analysed using an image quantifier (Cortex Controllers, England). This consists of a light microscope (Leitz) connected to a black and white video camera (Ikegami, Japan) which transfers the picture to a television monitor and to the image quantifier, which processes the black/white picture into a $\mathbf{1 6}$ grade colour scale, enabling differentiation between alcian blue positive and negative areas to be made. Fragments of gastric mucosa on each section were delineated with the help of a monitor and a
HIPAD Digitizer (Texas Instruments) and their area measured. The alcian blue positive areas were expressed as a proportion of the total gastric mucosa analysed in individual histological sections.

A non-parametric Kruskall Wallis test was used for statistical analysis.

\section{Results}

FUNDIC AND ANTRAL AREAS

A total of 254 measurements were made in the various gastric areas: 130 in the antral zone (I), 77 in the fundic area near the antrum (II), and 47 in the proximal fundic area (III). The results presented in table 1 show that the antral zone measured $571.53 \mathrm{~mm}^{2}$. The mean (SD) area occupied by alcian blue positive cells was $7 \cdot 50(9 \cdot 89) \%$.

The most proximal fundic area investigated measured $178.41 \mathrm{~mm}^{2}$. The alcian blue positive areas occupied $1.8(1.84) \%$ of the proximal fundic area.

Histological examination of preparations stained with haematoxylin and eosin indicated that zone II (figure) was also a fundic area. This area measured $267.8 \mathrm{~mm}^{2}$. Alcian blue positive areas amounted to $0.92(1 \cdot 15) \%$ of zone II.

The differences between the percentage of alcian blue positive cells in the antral zone were significantly higher $(p<0.001)$ than those of the fundic mucosa (zones II and III), but areas occupied by alcian blue positive cells in zone III were also significantly higher $(\mathrm{p}<0.001)$ than those present in zone II.

Table 1 Percentage of alcian blue positive areas in fundic and antral regions in one gastrectomy specimen with gastric peptic ulcer

\begin{tabular}{|c|c|c|c|}
\hline & \multicolumn{2}{|c|}{ Fundic region } & \multirow{2}{*}{$\begin{array}{l}\text { Antral } \\
\text { region }\end{array}$} \\
\hline & Proximal & Distal* & \\
\hline \multirow{3}{*}{$\begin{array}{l}\text { No of areas } \\
\text { Total mucosal area } \\
\left(\mathrm{mm}^{2}\right) \\
\text { Per cent alcian blue } \\
\text { area }\end{array}$} & 47 & 77 & 130 \\
\hline & $178 \cdot 41$ & $267 \cdot 8$ & $571 \cdot 53$ \\
\hline & $\begin{array}{c}1.8 \\
(\mathrm{SD} \pm 1.84)\end{array}$ & $\begin{array}{c}0.92 \\
(\mathrm{SD} \pm 1 \cdot 15)\end{array}$ & $\begin{array}{c}7 \cdot 5 \\
(\mathrm{SD} \pm 9.89)\end{array}$ \\
\hline
\end{tabular}

*Near antrum.

Table 2 Percentage of alcian blue positive areas along the lesser and greater curvatures in one gastrectomy specimen with gastric ulcer

\begin{tabular}{lcc}
\hline & $\begin{array}{l}\text { Lesser } \\
\text { curvature }\end{array}$ & $\begin{array}{l}\text { Greater } \\
\text { curvature }\end{array}$ \\
\hline No of areas & 43 & 64 \\
Total mucosal area $\left(\mathrm{mm}^{2}\right)$ & $150 \cdot 34$ & $190 \cdot 1$ \\
Per cent alcian blue area & $7 \cdot 76$ & $2 \cdot 17$ \\
& $(\mathrm{SD} \pm 12 \cdot 0)$ & $(\mathrm{SD} \pm 3.02)$ \\
\hline
\end{tabular}


LESSER AND GREATER CURVATURES

Of the 107 measurements carried out, 43 were made along the lesser curvature and 64 along the greater. The total mucosal area along the lesser curvature measured $150.34 \mathrm{~mm}^{2}$ and the mean alcian blue positive area found along this curvature was $\mathbf{7 . 7 6}$ $(12.0) \%$ (table 2). The total mucosal area measured along the greater curvature was $190.1 \mathrm{~mm}^{2}$ and the mean alcian blue positive area was $2 \cdot 17(3 \cdot 02) \%$.

The difference between the area occupied by alcian blue positive cells along the lesser curvature was significantly higher $(p<0.001)$ than along the greater curvature.

\section{Discussion}

Intestinal metaplasia in the gastric mucosa has been defined as the histological change consisting of three features: vacuolated mucin-producing cells, cylindrical cells with absorptive borders, and Paneth cells. $^{247-9}$ Some authors claim that such features may predate gastric carcinoma,,$^{1-8}$ but others ${ }^{6911}$ believe that they are concomitant.

To study the clinical importance of intestinal metaplasia in gastric carcinogenesis the extent and topographical distribution of the changes described in populations at high and low risk of developing a gastric carcinoma must be determined.

Our study of a single stomach with a benign ulcer indicates that the area with the most intestinal metaplasia occurred in the antral mucosa compared with other topographically different gastric areas. Metaplastic areas were also significantly larger along the lesser curvature than along the greater curvature, a finding which agrees with non-quantitative estimations of intestinal metaplasia presented by other authors. $^{4581314}$

Our method offers several advantages: (i) the method of sectioning the stomach is standardised; (ii) it permits the quantitation of areas with intestinal metaplasia in the stomach; (iii) it allows the comparison of areas with intestinal metaplasia in various gastric zones in different patients; (iv) it could be used to measure accurately the degree of intestinal metaplasia in populations with a disparate incidence of gastric carcinoma.

This study was supported by grants from the Karolinska Institute and the Cancer Society, Stockholm.
References

1 Elster K, Stolte M, Carson W, Eidt H. Metaplasia, dysplasia, and early gastric cancer. In: Si-Chun Ming, ed. Precursors of gastric cancer. New York: Praeger Publications, 1984:93-101.

2 Filipe MI, Potet F, Bogomoletz WV, et al. Incomplete sulphomucin secreting intestinal metaplasia for gastric cancer. Preliminary data from a prospective study from three centres. Gut 1985;26:1319-26.

3 Heilmann KL, Höpker WW. Loss of differentiation in intestinal metaplasia in cancerous stomachs. A comparative morphologic study. Path Res Pract 1979;164:249-58.

4 Hirota T, Okada T, Itabashi M, et al. Significance of intestinal metaplasia as a precancerous condition of the stomach. In: Si-Chun Ming, ed. Precursors of gastric cancer. New York: Praeger Publications, 1984:179-93.

5 Imai T, Kubo T, Watanabe $\mathrm{H}$. Chronic gastritis in Japanese without reference to high incidence of gastric carcinoma. $\mathrm{JNCI}$ 1971;47:179-95.

6 Imai T, Murayama H. Time trend in the prevalence of intestinal metaplasia in Japan. Cancer 1983;52:353-6.

7 Jass JR, Filipe MI. Sulphomucins and precancerous lesions of the human stomach. Histopathology 1980;4:271-9.

8 Matsukura N, Suzuki K, Kawachi T, et al. Distribution of marker enzymes and mucin in intestinal metaplasia in human stomach and relation of complete and incomplete types of intestinal metaplasia to minute gastric carcinomas. JNCI 1980;65:231-40.

9 Ming SC, Goldman H, Freiman DG. Intestinal metaplasia and histogenesis of carcinoma in human stomach. Light and electron microscopic study. Cancer 1967;20:1418-29.

10 Rubio CA, Kato Y, Sugano H, Kitagawa T. Intestinal metaplasia of the stomach. I: quantitative analysis in gastric peptic ulcer and in incipient adenocarcinoma in Japanese subjects. Anticancer Res 1985;5:435-40.

11 Rubio CA, Kato Y, Sugano H, Kitagawa T. Intestinal metaplasia of the stomach in Swedish and Japanese patients without ulcers or carcinoma. Jpn J Cancer Res (Gann) 1987;78:467-72.

12 Silva S, Filipe MI. Intestinal metaplasia and its variants in the gastric mucosa of Portuguese subjects: A comparative analysis of biopsy and gastrectomy material. Hum Pathol 1986;217: 988-95.

13 Sipponen P, Seppälä K, Varis K. Intestinal metaplasia with colonic-type sulphomucins in the gastric mucosa; its association with gastric carcinoma. Acta Pathol Microbiol Scand 1980;88:217-24.

14 Stemmermann GN, Hayashi T. Intestinal metaplasia of the gastric mucosa. JNCI 1968;41:627-34.

15 Turani H, Lurie B, Chaimoff $\mathrm{Ch}$, Kessler E. The diagnostic significance of sulfated acid mucin content in gastric intestinal metaplasia with early gastric cancer. Am J Gastroenterol 1986;81:343-5.

16 Rubio CA, Uribe A, Svensson A, May I. A method to quantitate intestinal metaplasia of the stomach by morphometry. Analyt Quant Cytol Histol 1988.

Requests for reprints to: Dr C A Rubio, Department of Pathology, Karolinska Sjukhuset, S-104 01 Stockholm, Sweden. 